\title{
Clinical analysis of prophylactic cholecystectomy during gastrectomy for gastric cancer patients: a retrospective study of 1753 patients
}

Zhenhua Tan, Ping Xie, Hai Qian and Xing Yao*

\begin{abstract}
Background: Performance of gastrectomy in gastric cancer patients can lead to an increased incidence of cholecystolithiasis $(\mathrm{CL})$ and a higher morbidity rate. However, the value of prophylactic cholecystectomy performed during gastric cancer surgery is still being debated.

Methods: We carried out a retrospective study on patients with gastric cancer who underwent subtotal or total gastrectomy, with preservation of the gallbladder or simultaneous cholecystectomy from January 2010 to March 2018.

Results: Cholecystolithiasis occurred in 152 of 1691 (8.98\%) patients after gastric cancer surgery, with 45 (2.67\%) patients undergoing subsequent cholecystectomy. Postoperative body mass index (BMI) decrease $>5 \%$ in 3 months was an independent risk factor for cholecystolithiasis [BMI decrease $>5 \% / \leq 5 \%$ : OR (95\%Cl): $1.812(1.225-2.681), p=$ 0.003). Gastrectomy method and diabetes mellitus were independent risk factors for both cholecystolithiasis [gastrectomy method (no-Billroth I/Billroth I): OR (95\%Cl): 1.801 (1.097-2.959), $p=0.002$; diabetes mellitus (yes/no): OR (95\%Cl): 1.544 (1.030-2.316), $p=0.036$ ] and subsequent cholecystectomy [gastrectomy method (no-Billroth I/ Billroth I): OR (95\%Cl): 5.432 (1.309-22.539), $p=0.020$; diabetes mellitus (yes/no): OR (95\%Cl): 2.136 (1.106-4.125), $p=$ 0.024]. Simultaneous cholecystectomy was performed in 62 of 1753 (3.5\%) patients. The mortality and morbidity rates did not differ significantly between the combined surgery group and the gastrectomy only group ( $8.1 \%$ vs. 8.9 and $1.6 \%$ vs. $2.2 \%$, respectively, $p>0.05$ ).
\end{abstract}

Conclusions: Prophylactic cholecystectomy may be necessary in gastric cancer patients without Billroth I gastrectomy and with diabetes mellitus. Simultaneous cholecystectomy during gastric cancer surgery does not increase the postoperative mortality and morbidity rates.

Keywords: Cholecystolithiasis, Gastric cancer, Subtotal gastrectomy, Prophylactic cholecystectomy

\section{Background}

It is generally accepted that performance of gastrectomy in gastric cancer patients can lead to an increased incidence of cholecystolithiasis $(\mathrm{CL})$ and a higher rate of morbidities that require secondary surgery [1], which may related with the complex interaction between sectioning of the nerve supply to the gallbladder and the change in cholecystokinin secretion [2, 3]. However, performance of routine prophylactic cholecystectomy during radical gastrectomy is still being debated [4]. The aim of this study was to investigate the correlative factors that contribute to gallstone formation and later cholecystectomy in patients with previous radical gastrectomy. The influences of simultaneous cholecystectomy on surgical mortality and morbidity of gastric cancer patients were also evaluated.

\footnotetext{
*Correspondence: yaoxingdoc@163.com

Department of Hepatobiliary Surgery, Huzhou Hospital, Zhejiang University

School of Medicine (Huzhou Central Hospital), No. 198, Hongqi Road,

Huzhou 313000, Zhejiang Province, China
}

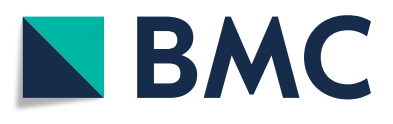

(c) The Author(s). 2019 Open Access This article is distributed under the terms of the Creative Commons Attribution 4.0 International License (http://creativecommons.org/licenses/by/4.0/), which permits unrestricted use, distribution, and reproduction in any medium, provided you give appropriate credit to the original author(s) and the source, provide a link to the Creative Commons license, and indicate if changes were made. The Creative Commons Public Domain Dedication waiver (http://creativecommons.org/publicdomain/zero/1.0/) applies to the data made available in this article, unless otherwise stated. 


\section{Methods}

\section{Patients}

A total of 1753 gastric cancer patients underwent radical gastrectomy at the Department of Surgery, Huzhou Hospital, Zhejiang University School of Medicine (Huzhou Central Hospital), China from January 2010 to March 2018. The diagnosis of gastric cancer was confirmed by postoperative pathological examination of the resected specimen. The study was approved by the Ethics Committee of Huzhou Hospital, Zhejiang University School of Medicine, and written informed consent was obtained from all patients. In all patients, 1691 had no gallstones and preserved their gallbladders during radical gastrectomy. These patients were all followed-up and the median follow-up period after first surgery was 45 months (range: 11-96 months). Their gallbladders were routinely examined by ultrasonography or computed tomography during the postoperative period and 152 patients were diagnosed $\mathrm{CL}$ after gastric resection. Of these patients, 45 patients underwent a secondary cholecystectomy followed the following surgical indications: cholecystolithiasis combined with conservative treatment of uncontrollable cholecystitis (more than 3 times per month); complicated with acute pancreatitis; gallstones larger than 2 $\mathrm{cm}$ in diameter; cholecystolithiasis combined with gallbladder polyp; porcelain gallbladder; gallbladder atrophy; gallbladder filling stones; gallstones located in the gallbladder ampulla abdomen or gallbladder duct. Sixty-two patients with gallstones underwent simultaneous cholecystectomy during radical gastrectomy. A flow chart for the treatment of the gastric cancer patients with or without cholecystolithiasis is shown in Fig. 1.

\section{Study protocol}

A total of 1691 gastric cancer patients without gallstones were evaluated retrospectively to determine the risk factors for cholecystolithiasis and later cholecystectomy. The clinicopathological characteristics of all patients were documented. The patients were grouped according to age ( $\leq 75 />75$ years), sex, rate of postoperative body mass index (BMI) decrease in 3 months [(preoperative BMI postoperative BMI 3 months after surgery) / preoperative $\mathrm{BMI} \times 100 \%](\leq 5 \% />5 \%), \mathrm{cTNM}$ stage, tumor differentiation grade, type of gastrectomy, extent of lymph node dissection, and presence of diabetes mellitus (yes/no). The tumor differentiation grades followed the criteria in the Edmondson-Steiner classification, and divided the patients into groups with well-differentiated tumors (Grade I), moderately-differentiated tumors (Grade II), and poorly-differentiated tumors (Grade III). Tumor stages were assigned according to the UICC TNM classification

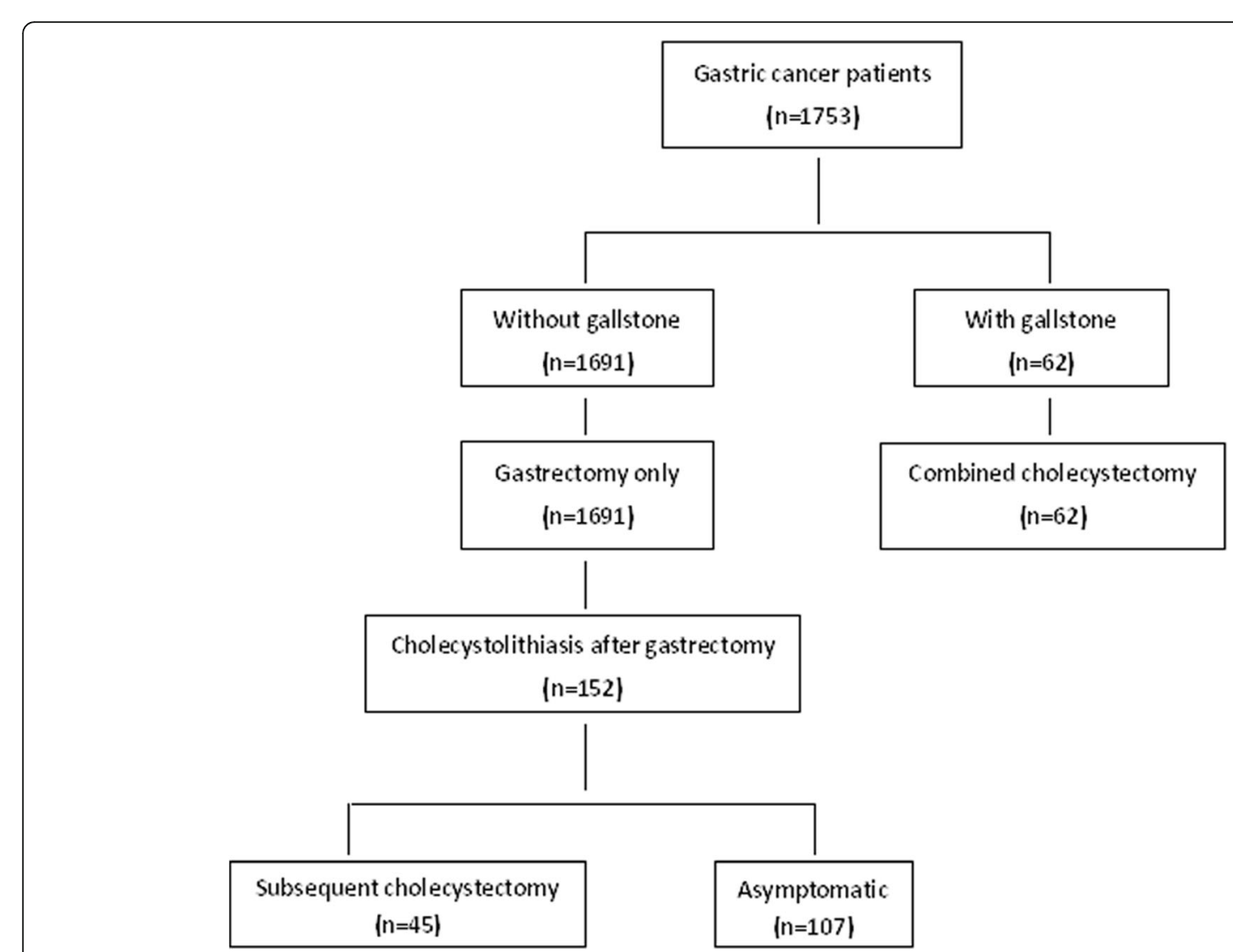

Fig. 1 Flow chart showing the treatment of the gastric cancer patients with or without cholecystolithiasis 
(7th edition). Then these groups were divided again to postoperative cholecystolithiasis (yes/no) and subsequent cholecystectomy (yes/no) groups for further study. The clinical outcomes of the 1691 patients who underwent gastrectomy only and the 62 patients who underwent combined surgery were reviewed retrospectively and documented, including postoperative mortality, postoperative wound infection, anastomotic leak, duodenal stump leak, gastric stasis, intraabdominal abscess, hemorrhage, pulmonary infection, diarrhea, postoperative pancreatitis, and cholangitis. The mortality and morbidity rates in the two groups were compared to determine the influence of simultaneous cholecystectomy on surgical safety of radical gastrectomy.

\section{Statistical analysis}

All data were prepared and compiled using SPSS software (version 19.0 for Windows; IBM Corp., Armonk, NY, USA). The Chi-square test and Fisher's exact test were used for quantitative data. Risk factors were analyzed by logistic regression analysis. A $p$-value $<0.05$ was considered statistically significant.

\section{Results}

\section{Patient characteristics}

The characteristics of the 1691 patients who did not undergo simultaneous cholecystectomy during gastric resection are shown in Table 1. The patients comprised 1222 males and 469 females, with a male-to-female ratio of 2.61:1 and an age range of 23-84 years (median age: 61 years). Regarding the gastric cancer stages, stage I was diagnosed in 534 (31.6\%) patients, stage II in 712 (42.1\%) patients, and stage III in 445 (26.3\%) patients. For tumor differentiation grades, Grade I was present in 617 (36.5\%) patients, Grade II in 523 (30.9\%) patients, and Grade III in 551 (32.6\%) patients. Billroth I reconstruction was performed in 334 (19.8\%) patients, Billroth II in 876 (51.8\%) patients, and total gastrectomy and Roux-en-Y reconstruction in 481 (28.4\%) patients. D1 lymph node dissections were carried out in 264 (15.6\%) patients, and D2 lymph node dissections in 1427 (84.4\%) patients. A total of 152 patients had gallstones after gastrectomy and the incidence of cholecystolithiasis was 8.98\% (152/1691). Forty-five patients underwent later cholecystectomy, giving a subsequent operation rate of $2.67 \%$ (45/1691).

\section{Risk factors fo $2 r$ cholecystolithiasis after gastrectomy}

The median interval from gastrectomy to development of cholecystolithiasis was 37.5 months (range: 8.0-94.7 months) and 152 patients had gallstones after gastrectomy, giving an incidence of cholecystolithiasis of $8.98 \%$. Univariate analyses showed that postoperative BMI decrease $>5 \%$ in 3 months, method of gastrectomy (Roux-en-Y, Billroth II), and diabetes mellitus were significantly associated with occurrence of gallstone formation $(p=0.002, p=0.018$, and $p=0.038$, respectively). Logistic regression analysis identified these
Table 1 Clinicopathological characteristics of 1691 gastric cancer patients who underwent gastrectomy without cholecystectomy (median age: $61.0 \pm 10.5$ years; age range: $23-$ 84 years)

\begin{tabular}{ll}
\hline Variable & No. of patients (\%) \\
\hline Gender & \\
Male & $1222(72.3 \%)$ \\
Female & $469(27.7 \%)$ \\
TNM stage & \\
Stage I & $534(31.6 \%)$ \\
Stage II & $712(42.1 \%)$ \\
Stage III & $445(26.3 \%)$ \\
Tumor differentiation grade & \\
Grade I & $617(36.5 \%)$ \\
Grade II & $523(30.9 \%)$ \\
Grade III & $551(32.6 \%)$ \\
Method of gastrectomy & \\
Billroth I & $334(19.8 \%)$ \\
Billroth II & $876(51.8 \%)$ \\
Roux-en-Y & $481(28.4 \%)$ \\
Lymph node dissection & \\
D1 & $264(15.6 \%)$ \\
D2 & $1427(84.4 \%)$ \\
Cholecystolithiasis after gastrectomy & $152(8.98 \%)$ \\
Subsequent cholecystectomy after gastrectomy & $45(2.67 \%)$ \\
\hline
\end{tabular}

clinicopathological features as risk factors for occurrence of cholecystolithiasis after gastrectomy [BMI decrease (> 5\%/ $\leq 5 \%)$ : OR (95\%CI): 1.812 (1.225-2.681), $p=0.003$; gastrectomy method (no-Billroth I/Billroth I): OR (95\%CI): 1.801 (1.097-2.959), $\quad p=0.002$; diabetes mellitus (yes/no): OR (95\%CI): $1.544(1.030-2.316), p=0.036]$, as shown in Table 2.

\section{Risk factors for subsequent cholecystectomy after gastrectomy}

A total of $45(2.67 \%)$ patients required a subsequent cholecystectomy after gastrectomy. Of these, 34 patients underwent open cholecystectomy and 11 patients underwent laparoscopic cholecystectomy. Univariate analyses showed that method of gastrectomy (Roux-en-Y, Billroth II) and diabetes mellitus were significantly associated with occurrence of later cholecystectomy ( $p=0.007$ and $p=0.038$, respectively). Logistic regression analysis identified these two clinicopathological features as risk factors for occurrence of subsequent cholecystectomy [gastrectomy method (no-Billroth I/Billroth I]: OR (95\%CI): 5.432 (1.309-22.539), $p=0.020$; diabetes mellitus (yes/no): OR (95\%CI): 2.136 (1.106-4.125), $p=$ 0.024 , as shown in Table 3. 
Table 2 Correlations between the clinicopathological characteristics of 1691 gastric cancer patients and postoperative cholecystolithiasis

\begin{tabular}{|c|c|c|c|c|c|c|}
\hline \multirow[t]{2}{*}{ Variables } & \multicolumn{2}{|c|}{ Postoperative cholecystolithiasis } & \multirow[t]{2}{*}{$x^{2}$} & \multirow{2}{*}{$\begin{array}{l}p \\
\text { value }\end{array}$} & \multirow{2}{*}{$\begin{array}{l}\text { Odds ratio (95\% } \\
\mathrm{Cl})\end{array}$} & \multirow{2}{*}{$\begin{array}{l}p \\
\text { value }\end{array}$} \\
\hline & Yes $(n=152)$ & No $(n=1539)$ & & & & \\
\hline \multicolumn{7}{|l|}{ Age (years) } \\
\hline$>75$ & 34 & 412 & 1.381 & 0.288 & & \\
\hline$\leq 75$ & 118 & 1127 & & & & \\
\hline \multicolumn{7}{|l|}{ Gender } \\
\hline Male & 105 & 1117 & 0.846 & 0.393 & & \\
\hline Female & 47 & 422 & & & & \\
\hline \multicolumn{7}{|c|}{ BMI decreased rate } \\
\hline$\leq 5 \%$ & 35 & 541 & 9.057 & $0.002^{*}$ & 1 & $0.003^{*}$ \\
\hline$>5 \%$ & 117 & 998 & & & $1.812(1.225-2.681)$ & \\
\hline \multicolumn{7}{|l|}{ TNM stage } \\
\hline Stage I+ II & 114 & 1132 & 0.149 & 0.699 & & \\
\hline Stage III & 38 & 407 & & & & \\
\hline \multicolumn{7}{|c|}{ Tumor differentiation grade } \\
\hline Grade I+ II & 96 & 1044 & 1.378 & 0.240 & & \\
\hline Grade III & 56 & 495 & & & & \\
\hline \multicolumn{7}{|c|}{ Method of gastrectomy } \\
\hline Billroth I & 19 & 315 & 5.541 & $0.018^{*}$ & 1 & $0.002^{*}$ \\
\hline No-Billroth I & 133 & 1224 & & & $1.801(1.097-2.959)$ & \\
\hline \multicolumn{7}{|c|}{ Lymph node dissection } \\
\hline D1 & 30 & 234 & 2.157 & 0.159 & & \\
\hline D2 & 122 & 1305 & & & & \\
\hline \multicolumn{7}{|c|}{ Diabetes mellitus } \\
\hline No & 118 & 1297 & 4.471 & $0.038^{*}$ & 1 & $0.036^{*}$ \\
\hline Yes & 34 & 242 & & & $1.544(1.030-2.316)$ & \\
\hline
\end{tabular}

Postoperative morbidity and mortality rates in the simultaneous cholecystectomy group and gastrectomy only group

Of the total 1793 gastric cancer patients, 62 (3.5\%) patients with gallstones underwent simultaneous cholecystectomy during gastric resection. The mortality and morbidity rates did not differ significantly between the combined surgery group and the gastrectomy only group (8.1\% vs. 8.9 and $1.6 \%$ vs. $2.2 \%$, respectively, $p>0.05$ ), as shown in Table 4 .

\section{Discussion}

Patients undergoing gastrectomy, especially radical gastrectomy, have a higher incidence of postoperative gallstone formation $[5,6]$. The underlying mechanisms of this phenomenon are unclear. The complex interaction between the supply of cholecystic nerves and the secretion of cholecystokinin may play an important role. In gastric cancer surgery, to achieve better lymph node dissection, the liver branch of the vagus nerve is inevitably damaged. Deletion or damage to the vagus nerve branch can result in impaired gallbladder emptying, which in turn may lead to gallstone formation [7, 8]. Also, radical gastrectomy usually involves Billroth II and Roux-en-Y techniques, which eliminate food passing through the duodenum, and may reduce secretion of cholecystokinin and gallbladder activity, promoting cholestasis and gallstone formation [2]. Although several studies confirmed that the incidence of gallstones after gastrectomy is significantly higher than that in patients without upper gastrointestinal surgery, whether there is a need for preventive gallbladder resection in gastric cancer surgery remains controversial. The incidence of gallstones and symptomatic cholelithiasis requiring cholecystectomy after gastric cancer surgery is still relatively low [9]. In the present study, we observed cholecystolithiasis after gastrectomy in only $8.98 \%$ of patients, which was lower than the rates of $13-22 \%$ reported in previous studies [2, $4,6]$. We also found a low incidence of subsequent cholecystectomy of only $2.67 \%$ of patients. Based on these data, we believe that not all patients undergoing 
Table 3 Correlations between the clinicopathological characteristics of 1691 gastric cancer patients and subsequent cholecystectomy

\begin{tabular}{|c|c|c|c|c|c|c|}
\hline \multirow[t]{2}{*}{ Variables } & \multicolumn{2}{|c|}{ Subsequent cholecystectomy } & \multirow[t]{2}{*}{$x^{2}$} & \multirow{2}{*}{$\begin{array}{l}p \\
\text { value }\end{array}$} & \multirow[t]{2}{*}{ Odds ratio $(95 \% \mathrm{Cl})$} & \multirow{2}{*}{$\begin{array}{l}p \\
\text { value }\end{array}$} \\
\hline & Yes $(n=45)$ & No $(n=1646)$ & & & & \\
\hline \multicolumn{7}{|l|}{ Age (years) } \\
\hline$>75$ & 11 & 435 & 0.089 & 0.865 & & \\
\hline$\leq 75$ & 34 & 1211 & & & & \\
\hline \multicolumn{7}{|l|}{ Gender } \\
\hline Male & 32 & 1190 & 0.031 & 0.867 & & \\
\hline Female & 13 & 456 & & & & \\
\hline \multicolumn{7}{|c|}{ BMI decreased rate } \\
\hline$\leq 5 \%$ & 9 & 567 & 4.071 & 0.055 & & \\
\hline$>5 \%$ & 36 & 1079 & & & & \\
\hline \multicolumn{7}{|l|}{ TNM stage } \\
\hline Stage I+ II & 32 & 1214 & 0.158 & 0.732 & & \\
\hline Stage III & 13 & 432 & & & & \\
\hline \multicolumn{7}{|c|}{ Tumor differentiation grade } \\
\hline Grade I + II & 32 & 1108 & 0.287 & 0.633 & & \\
\hline Grade III & 13 & 538 & & & & \\
\hline \multicolumn{7}{|c|}{ Method of gastrectomy } \\
\hline Billroth I & 2 & 332 & 6.834 & $0.007^{*}$ & 1 & $0.020^{*}$ \\
\hline No-Billroth I & 43 & 1314 & & & $5.432(1.309-22.539)$ & \\
\hline \multicolumn{7}{|c|}{ Lymph node dissection } \\
\hline D1 & 10 & 254 & 1.533 & 0.213 & & \\
\hline D2 & 35 & 1392 & & & & \\
\hline \multicolumn{7}{|c|}{ Diabetes mellitus } \\
\hline No & 32 & 1383 & 5.346 & $0.038^{*}$ & 1 & $0.024^{*}$ \\
\hline Yes & 13 & 263 & & & $2.136(1.106-4.125)$ & \\
\hline
\end{tabular}

Table 4 Postoperative morbidity and mortality rates in the simultaneous cholecystectomy group and the gastrectomy only group

\begin{tabular}{|c|c|c|c|c|}
\hline & Simultaneous cholecystectomy $(n=62)$ & Gastrectomy only $(n=1691)$ & $x^{2}$ & $p$ value \\
\hline Postoperative morbidity & $8.1 \%(4.9)$ & $8.9 \%(145)$ & 0.021 & 0.997 \\
\hline Wound infection & $8.1 \%(5)$ & $8.7 \%(147)$ & 0.030 & 0.991 \\
\hline Hemorrhage & $3.2 \%(2)$ & $3.3 \%(55)$ & 0.021 & 0.998 \\
\hline Anastomotic leak & $6.4 \%(4)$ & $7.2 \%(121)$ & 0.045 & 0.997 \\
\hline Duodenal stump leak & $1.6 \%(1)$ & $1.7 \%(29)$ & 0.031 & 0.992 \\
\hline Gastric stasis & $12.8 \%(8)$ & $14.8 \%(251)$ & 0.179 & 0.855 \\
\hline Intraabdominal abscess & $3.2 \%(2)$ & $3.1 \%(52)$ & 0.022 & 0.998 \\
\hline Pulmonary infection & $6.4 \%(4)$ & $6.7 \%(114)$ & 0.008 & 0.998 \\
\hline Diarrhea & $17.7 \%(11)$ & $17.4 \%(295)$ & 0.004 & 1.000 \\
\hline Postoperative cholangitis & $8.1 \%(5)$ & $9.6 \%(162)$ & 0.159 & 0.828 \\
\hline Postoperative pancreatitis & $11.3 \%(7)$ & $13.2 \%(224)$ & 0.200 & 0.848 \\
\hline Postoperative mortality & $1.6 \%(1)$ & $2.2 \%(38)$ & 0.111 & 1.000 \\
\hline
\end{tabular}


gastrectomy require routine preventive cholecystectomy. However, our identification of risk factors leading to gallstone formation and subsequent cholecystectomy is important and can help surgeons develop a rational surgical treatment strategy to avoid subsequent surgery or over-treatment.

Various clinical or surgical factors appear to be responsible for the development of cholecystolithiasis or the requirement for subsequent cholecystectomy after radical gastrectomy. Regarding surgical methods, several studies reported that the incidence of gallstone formation was affected by the gastrectomy procedure, especially the type of gastrointestinal reconstruction [10]. A recently study found that in patients who underwent distal gastrectomy, there are no significant difference in gallstones incidence between performance of Billroth I, Billroth II, or Roux-en-Y anastomosis, but most research results indicated that the incidence of gallstones is higher in patients with Biroth II and Roux-en-Y anastomosis (duodenal exclusion) [11] and the patients who underwent total gastrectomy with resection of the esophagus and complete vagus nerve stem [12].

Lymph node dissection during radical gastrectomy is another possible risk factor for gallstone formation and subsequent cholecystectomy. Some studies have shown that the degree of lymph node dissection has an influence on gallstone formation [8]. More involved lymph node dissections are associated with a higher incidence of gallstones and acute cholecystitis following subsequent surgery than with limited or standard lymph node dissection. D2 lymph node dissection includes dissection along the hepatoduodenal ligament, which may lead to gallstones or cholecystitis by affecting gallbladder emptying, but routine concomitant cholecystectomy and D2 lymph node dissection remains controversial [13]. Surgical techniques, age, BMI reduction after gastrectomy, and diabetes are candidate risk factors for gallstone formation after gastrectomy. Rapid weight loss can also lead to mobilization of cholesterol stored secondary to gallbladder bile deposition. Supersaturation, as well as cholestasis secondary to bile duct inflammation, can promote gallstone formation [14].

The effect of diabetes on gallstones is multifactorial; diabetes leads to neuritis and neuromyopathy. In diabetes, increased oxidative stress at low heme oxygenase-1 levels and decreased insulin and insulin-like growth factor-1 signaling lead to loss of interstitial cells of Cajal, which results in abnormal gallbladder emptying and promotes gallstone formation [15]. Diabetes mellitus is also a well-known risk factor for cholelithiasis, which can lead to subsequent cholecystectomy [16].

In this retrospective study, we applied Fisher's exact test and logistic regression analysis to identify the risk factors for gallstone formation and subsequent cholecystectomy after radical gastrectomy, and found that postoperative BMI decrease $>5 \%$ in 3 months, gastrectomy method (Roux-en-Y or Billroth II), and diabetes mellitus were independent risk factors for cholecystolithiasis. Roux-en-Y or Billroth II reconstruction and diabetes mellitus were also independent risk factors for subsequent cholecystectomy. These results indicated that prophylactic cholecystectomy may be necessary in patients with Roux-en-Y or Billroth II gastrectomy and with diabetes mellitus. $\mathrm{H}$ However, some studies reported that the postoperative complication incidences of simultaneous cholecystectomy during gastrectomy is higher than which of late cholecystectomy [12]. In our study, there was no significant increase in postoperative morbidity or mortality in patients who underwent cholecystectomy during radical gastrectomy.

In summary, prophylactic and simultaneous cholecystectomy during gastric resection for gastric cancer patients is safe, but does not need to be a routine operation for all patients undergoing radical gastrectomy; however, this approach may be recommended in patients undergoing Roux-en-Y or Billroth II reconstruction or in patients with diabetes mellitus.

The limitations and possible biases of this study are lack of randomization as a retrospective study, which may cause selective bias. In some groups, the small number of patients may make detection of small differences between study groups unreliable.

\section{Conclusions}

This study showed that prophylactic cholecystectomy may be necessary in gastric cancer patients without Billroth I gastrectomy and with diabetes mellitus. Simultaneous cholecystectomy during gastric cancer surgery does not increase the operative mortality and morbidity rates.

\section{Abbreviations}

BMI: body mass index; CL: cholecystolithiasis

\section{Acknowledgements}

We thank Dr. Mingjie Zhang (MD) from Huzhou Hospital, Zhejiang University School of Medicine (Huzhou Central Hospital) for introducing appropriate statistical analysis methods. We also thank Alison Sherwin, PhD, from Liwen Bianji, Edanz Editing China (http://www.liwenbianji.can/ac) for editing the English text of a draft of this manuscript.

\section{Funding}

None.

Availability of data and materials

All of the data are available without restriction. Researchers can obtain data by contacting the corresponding author.

\section{Authors' contributions}

ZT and XY designed the study. HQ and ZT performed the data acquisition and analysis. PX performed the statistical analysis and data interpretation. ZT

prepared the manuscript. All authors read and approved the final manuscript.

Ethics approval and consent to participate

This study was approved by the Ethics Committee of Huzhou Central Hospital (HzhcLS2017-123), and the procedures were in compliance with Helsinki Declaration. Written informed consent forms about the procedure were obtained for all patients before surgery. 


\section{Consent for publication}

Not applicable.

\section{Competing interests}

The authors declare that they have no competing interests.

\section{Publisher's Note}

Springer Nature remains neutral with regard to jurisdictional claims in published maps and institutional affiliations.

Received: 8 July 2018 Accepted: 3 May 2019

Published online: 14 May 2019

\section{References}

1. Chen Y, Li Y. Related factors of postoperative gallstone formation after distal gastrectomy: a meta-analysis. Indian J Cancer. 2017;54(1):43-6.

2. L Liang TJ, Liu SI, Chen YC, Chang PM, Huang WC, Chang HT, Chen IS. Analysis of gallstone disease after gastric cancer surgery. Gastric Cancer. 2017;20(5):895-903.

3. Paik KH, Lee JC, Kim HW, Kang J, Lee YS, Hwang JH, Ahn SH, Park DJ, Kim $\mathrm{HH}$, Kim J. Risk factors for gallstone formation in resected gastric Cancer patients. Medicine. 2016;95(15):e3157.

4. Lai SL, Yang JC, Wu JM, Lai IR, Chen CN, Lin MT, Lai HS. Combined cholecystectomy in gastric cancer surgery. International journal of surgery (London, England). 2013;11(4):305-8.

5. Hauters P, de Neve de Roden A, Pourbaix A, Aupaix F, Coumans P, Therasse G. Cholelithiasis: a serious complication after total gastrectomy. Br J Surg. 1988;75(9):899-900.

6. Lorusso D, Misciagna G, Noviello MR, Tarantino S. Cholelithiasis after Billroth II gastric resection. Surgery. 1988;103(5):579-83.

7. Cariati A, Piromalli E, Cetta F, Andorno E. Black or Brown pigment and cholesterol gallstones formation among patients that underwent gastrectomy for Cancer. World J Surg. 2017;41(10):2642.

8. Furukawa H, Ohashi M, Honda M, Kumagai K, Nunobe S, Sano T, Hiki N. Preservation of the celiac branch of the vagal nerve for pylorus-preserving gastrectomy: is it meaningful? Gastric cancer : official journal of the International Gastric Cancer Association and the Japanese Gastric Cancer Association. 2018;21(3):516-23.

9. Miftode SV, Troja A, El-Sourani N, Raab HR, Antolovic D. Simultaneous cholecystectomy during gastric and oesophageal resection: a retrospective analysis and critical review of literature. Int J Surg. 2014;12(12):1357-9.

10. Nakamura K, Ogoshi K, Makuuchi H. Clinicopathological study of cholelithiasis following gastric cancer surgery. Eur Surg Res. 2005;37(1):29-35.

11. Fukagawa T, Katai H, Saka M, Morita S, Sano T, Sasako M. Gallstone formation after gastric Cancer surgery. J Gastrointest Surg. 2009;13(5):886-9.

12. Gillen S, Michalski CW, Schuster T, Feith M, Friess H, Kleeff J. Simultaneous/ incidental cholecystectomy during gastric/esophageal resection: systematic analysis of risks and benefits. World J Surg. 2010;34(5):1008-14.

13. Akatsu T, Yoshida M, Kubota T, Shimazu M, Ueda M, Otani Y, Wakabayashi G, Aiura K, Tanabe M, Furukawa T, et al. Gallstone disease after extended (D2) lymph node dissection for gastric cancer. World J Surg. 2005;29(2):182-6.

14. Cabarrou P, Portier G, Du Rieu MC. Prophylactic cholecystectomy during abdominal surgery. Journal Of Visceral Surgery. 2013;150(4):229-35.

15. Biddinger SB, Haas JT, Yu BB, Bezy O, Jing EX, Zhang WW, Unterman TG, Carey MC, Kahn CR. Hepatic insulin resistance directly promotes formation of cholesterol gallstones. Nat Med. 2008;14(7):778-82.

16. Sasazuki S, Kono S, Todoroki I, Honjo S, Sakurai Y, Wakabayashi K, Nishiwaki M, Hamada H, Nishikawa H, Koga H, et al. Impaired glucose tolerance, diabetes mellitus, and gallstone disease: an extended study of male selfdefense officials in Japan. Eur J Epidemiol. 1999;15(3):245-51.

Ready to submit your research? Choose BMC and benefit from:

- fast, convenient online submission

- thorough peer review by experienced researchers in your field

- rapid publication on acceptance

- support for research data, including large and complex data types

- gold Open Access which fosters wider collaboration and increased citations

- maximum visibility for your research: over $100 \mathrm{M}$ website views per year

At $\mathrm{BMC}$, research is always in progress.

Learn more biomedcentral.com/submissions 